\title{
ANIMAÇÃO TURÍSTICA Um Fenômeno da Moda?
}

\author{
Luiz Octávio de Lima CAMARGO* \\ Marilia Gomes dos Reis ANSARAH ${ }^{* *}$
}

\begin{abstract}
RESUMO: ^borda a origem e evolução da animação no contexto do Turismo, analisando: os três tempos da animação turística (antes, durante. depois); o animador turístico. Discute em destaque a animação em organização hoteleira. e sugere a necessidade de uma adequada formaçāo de recursos humanos nárea.
\end{abstract}

UNITERMOS: Turismo: animação. Animação turística: origem; evolução, animador. Hotéis: animação.

ABSTRACT: Approaches the origin and erolution of animation in the tourism context analizing: the three periods of touristic animation (before, during and after); the turistic leader. Discusses in prominence the animation of hotel keeping animation and suggests the necessity of on adequate formation of human resources in the area.

KEY WORDS: Tourism: animation. Turistic animation: origin; erolution; leader. Hotel: animation.

\section{INTRODUÇÃO}

Turismo é mudança de ritmo, paisagem e estilo de vida. Isto poderia soar banal, não fosse a constatação de que as pessoas "educadas" para o ritmo de trabalho têm dificuldade em amenizar o passo e esquecer o relógio em situação de lazer, especialmente quando este lazer

$\left(^{*}\right)$ Doutor em Ciências da Educação pela Universidade Sorbone, Paris. Gerente da empresa Tempolivre Consultoria e Projetos Culturais S/C Ltda. Coordenador do Curs de São Paulo.

End. para corresp.: Rua Dr. Renato Paes de Barros, 56 - AN 16-04530 - São Paulo - SP - Brasil.

(**) Mestre em Ciências da Comunicação pela Escola de Comunicaçōes e Artes da USP. Supervisora de Curso da Secretaria Municipal de Cultura, conveniada no Departamento de Relaçōes Públicas. Propaganda e Turismo da ECAJSP. Professora Titular e Coordenadora do Curso Superior de Turismo na Universidade Paulista.

End. para corresp.: Rua Cláudio, 422 - Água Branca - 05043 - São Paulo - SP - Brasil. 
é turístico; de que as pessoas, habituadas ao tudo-pronto e ao artificialismo das cidades, experimentam grandes dificuldades quando não a impossibilidade pura e simples de apreciar o novo que a experiência turística propicia; de que as pessoas em geral temem ou cvitam, (ao invés de apreciar e buscar) um estilo de vida que os afastem de sua rotina cotidiana.

Esclarecendo um pouco mais: os uiltimos duzentos anos deste milênio foram dedicados ao trabatho co aprendizado do trabalho. Identificamo-nos uns aos outros pelo trabalho profissional que executamos ao inv'és de atividades que nos gratificam. Somos, pois, preparados para o trabalho, a obrigaçào, a tensào, a competiçào, para a produtividade (fazer o máximo de coisas ao menor tempo possírel). Situaçies de lazer, de prazer, de relaxamento, de contato aparentemente banal, de improdutivida. de (fazer o mínimo de coisas no maior tempo possí'el) colocam muitos de nós em situação de constrangimento quando näo de mal-estar. Ora, as naçìes desenvolvi-

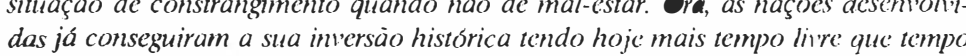
de trabalho. Em países subdesenvolvidos, também caminhamos na dirę̧üo dessa mudança. Assim, se nada for feito, teremos pesseas desajustadas cxatamente no tempo criado para se "wiver a vida"."

Em nome dessa preocupação, surgiram as técnicas de animação cultural, ou seja, técnicas de ação que visam permitir às pessoas formas de desfrute de tempo livre mais adequadas aos estímulos de prazer e de afirmação das aspirações pessoais, que estão na origem de toda busca de lazer.

As instituiçōes de lazer em geral já abandonaram a postura ingênua de imaginar que bastam as instalações e as facilidades, para que as pessoas lotem os espaços. Sabem que há necessidade de uma mediação educativa e criativa entre a oferta de bens e serviços de lazer e a sua procura; ou seja, de que há necessidade de animação. Atualmente este fato já é realidade em centros culturais, clubes públicos e de cmpresas, parques públicos e privados etc.

O setor turístico no Brasil vem atentando nos últimos anos para essa necessidade. O hotel Mediterranée, ainda que sua proposta seja discutível, teve ao menos o mérito de "acordar" os hoteleiros para a evidência de que o investimento em animação (equipamentos e recursos humanos) pode ajudar para a melhoria de seus lucros. Hoje quase todos os grandes hotéis de lazer estão se aparelhando para essa necessidade, com equipes próprias ou contratadas. Com isso, o número de micro-empresas que surgem para dar conta dessa necessidade é uma outra evidência de que a animação turística ou hoteleira chega finalmente à ordem do dia das preocupaçōes empresariais.

Este artigo procura suprir a inexistência de literatura sobre o assunto. É um vôo rápido sobre o tema, para dar conta de suas dimensões. Inicia-se com um esforço de conceituação, seguido de uma 32 breve descrição de métodos e instrumentais, e finaliza com os aspectos gerenciais da atividade. Na conclusão, abordam-se as perspectivas que se colocam para este novo campo de ação.

\section{QUE É ANIMAÇÃO TURÍSTICA?}

O termo animação turística aparece aplicado às atividades cujo único sentido em comum consiste em que se desenvolvam dentro de âmbitos turísticos. Denota, sem dúvida, a ausência de uma definição que sirva de referência aos que utilizam geralmente de maneira indiscriminada e com a freqüência inadequada, favorecendo a confusão em torno do real significado e atividades a que se refere.

Esta é, provavelmente, uma das causas da desvalorização que sofre a animação turística, tão utilizada pelos numerosos empresários e profissionais do setor, inclusive pelo próprio turista, que desconhece sua real importância e a considera, na melhor das hipóteses, como um instrumento "marginal", ornamental e acessório da verdadeira e essencial atividade turística.

Etimologicamente animação é entendida como vivacidade, movimentação, dinamização e motivação da participaçāo e está sendo aceita em alguns países, inclusive no Brasil, aplicada em diversos campos. Procede, por extensão, da animação sócio-cultural, de origem francesa, da qual se considera uma especialização no campo do tempo livre.

A animação sócio-cultural motiva e dinamiza os processos de participação ativa dos indivíduos e grupos nos fenômenos sociais e culturais que os implicam, desenvolvendo sua integração. Um dos campos de ação mais claros onde se desenvolve é no tempo livre, pois é aqui, sem dúvida, onde se exercita a maior parte do tempo não laboral e, portanto, mais disponível do homem de nossos dias.*

Nas viagens de férias, o turismo é hoje em dia parte fundamental, ou talvez, a mais importante, ou a que o citadino atribui a maior consideração, em seu tempo livre, nas sociedades desenvolvidas. Daí a absoluta justificação da denominação animação turística, que, para

(*) Entende-se por tempo livre aquele tempo do qual dispōe o indivíduo fora de suas necessidades inevitáveis e obrigações profissionais, familiares. sociais e cívicas. não se confundindo com o tempo desocupado dos desempregados. sociais e civicas. näo lidos, para realizar atividades discricionais, on seja conforme su livre escollo racterizada por um tive " escolla. ca- 
Fernando de la Riva (primeiro diretor de animaçào, em Madrid):

é o conjunto de açòes e técnicas dirigidas a motivar, promover e facilitar a maior e mais ativa participação do turista no desfrute e aproveitamento de seu tempo turístico, em todos os níveis e dimensöes que este implica.

Fala-se, portanto, de ações e técnicas, o que exclui casualidade e improvisação. A animação turística dá-se em pleno sentido quando é resultado de uma vontade consciente que se materializa em projetos, estratégias e ações concretas desenvolvidas mediante técnicas específicas e adequadas. Exige um nível de aprofundamento, estudo e profissionalismo, que na realidade não ocorre.

Na definição acima Riva refere-se, também, a motivar, promover e facilitar. Em animação turística não basta que a oferta turística exista, pois o turista, por seus próprios condicionamentos sócio-culturais e pelo turismo realizar-se durante tempos curtos e em espaços e lugares desconhecidos para ele, não tem freqüentemente a capacidade necessária para aproveitar, por seu próprio impulso, todas as possibilidades que a oferta contem. Faz-se necessário, então, motivar sua atenção, promover seu interesse e facilitar os instrumentos para que o exercite.

O objetivo será conseguir "uma maior e mais ativa participação do turista no desfrute e aproveitamento de seu tempo turístico"2. Não existem, portanto, expectadores passivos. O turismo não é estéril, é um modo vivo de comunicação e intercâmbio de relação e conhecimento de emoções, sensações e experiências, que exigem uma atividade ativa, curiosa e dinâmica por parte de seu único protagonista possível - o turista. O turista não pode ser tão somente um número dentro de uma massa, anônimo e impessoal, pelo contrário, possui características peculiares determinadas por sua origem geocultural e social que precisam ser consideradas.

Somente quando ele aproveitar ao máximo as possibilidades de uma experiência gratificante é que se chega ao desfrute, ao prazer, à satisfação.

A animação turística é absolutamente inseparável do jogo, do lúdico, entendido em seu sentido mais amplo. Representa, sem dúvida, a melhor resposta a certos "empiristas" da animação turística que, por desconhecimento, a consideram contrária à rentabilidade econômica, duvidando que os maiores índices de satisfação são os que produzem mais altos benefícios a curto, médio e a longo prazo, em todos os níveis.

Riva aborda, por último, em seu conceito, todos os niveis e dimensões do tempo turístico ${ }^{2}$, porque parece oportuno fugir daquelas concepções de animação turística que a restringem ao campo do entretenimento, das festas, das atividades noturnas e, ainda, das atividades desportivas. As viagens no tempo livre, são, sem dúvida, entretenimento, descanso e exercício físico.

O turismo é convivência, cultura, folclore, artesanato e costumes, paisagem etc. Limitar animação turística à ocupação recreativa do tempo livre pode ser opção economicamente rentável, mas é insuficiente para cobrir todas as possilibidades que o turismo oferece e todo o acúmulo de necessidades que o turista apresenta. É necessário, então, estender a animação nos âmbitos estatal, regional, local, empresarial etc., a todos os níveis e dimensöes, sociais, culturais e recreativas, que o turismo implica. A rica diversidade de nossa cultura não faz senão multiplicar os atrativos da oferta e, portanto, suas possibilidades de aproveitamento e desfrute, sua capacidade de ser "animada". A cada dia são mais importantes as iniciativas que se põem em marcha, tendo como protagonistas importantes cadeias hoteleiras e organizações turísticas. Este é o momento para se começar a trabalhar na direção correta, a fim de que todos os profissionais do setor turístico atuem conscientemente sobre a enorme importância que a animação turística representa.

\section{OS TRÊS TEMPOS DA ANIMAÇÃO TURÍSTICA}

Toda atividade de lazer programada por algum indivíduo gera no mesmo três tempos de vivência da atividade: o antes, o durante e o depois. Ir assistir a um filme suscita um tempo de preparação, no qual o indivíduo se interessa por críticas de jornais, comentários de amigos etc. e um tempo de "graça" posterior, no qual ele "rumina" os melhores momentos, seleciona frases e observações para discussão com os amigos etc.

Todavia, em nenhum momento de lazer esses tempos permanecem de forma tão marcante como no turismo. E quanto maior é a sua dimensão, mais preciosos são esses tempos.

\subsection{Antes}

Este tempo é importante para a animação. Nele os indivíduos estão disponíveis e preparados para qualquer ação que, do seu ponto de vista, sirva para alimentar a agradável sensação de ansiedade que os toma.

Um bom animador turístico vislumbra aqui as condições mais adequadas para o seu trabalho. Uma pesquisa de interesses, uma 
pesquisa/divulgação de informações sobre o local/alvo da visitação turística, uma reuniāo prévia (em caso de grupo fechado) para exibição de "slides" sobre o local a ser visitado ou para a criação de uma ambiência associativa, são iniciativas que têm grandes possibilidades de êxito.

O momento em que o cliente se inscreve para uma viagem ou para uma estada num hotel já o credencia como cliente da animação turística. Mas pode-se imaginar também uma animação prévia, quase assemelhada a uma divulgação do projeto turístico, com grandes possibilidades de êxito, em escolas, empresas, grupos de terceira idade e grupos em geral.

De qualquer forma, a criatividade do animador é que decidirá a melhor forma de aproveitar esse primeiro tempo de expectativas que se abre para uma autêntica educação ao turismo.

\subsection{Durante}

Às vezes, o animador turístico é confundido com o "chato" que quer a todo custo que as pessoas dancem, participem de atividades um risco e um equívoco a ser afastado. O objetivo da animação é permitir que as pessoas desfrutem da melhor forma possível de sua viagem ou estada num hotel. Mas, isso supõe, na maioria dos casos, o respeito à privacidade que muitos apreciam e às vezes buscam com esforço numa viagem ou num hotel de lazer. Essas pessoas necessitam atividades calmas ou individuais, como uma leitura, um contato com seus "iguais" profissionais ou afetivos, mais do que tentativas de os fazer participar a qualquer custo de atividades que eles não apreciam.

Contudo, deve-se ressalvar que a maior parte das pessoas contabiliza seus ganhos culturais numa viagem ou numa estada em hotel de lazer pelas risadas, pelas estórias, pelos contatos, pelas paqueras. Tais pessoas apreciam atividades movimentadas e barulhentas, um amplo leque de atividades que vão dos jogos formais às atividades recreativas, às gincanas, aos bailes, às esquetes teatrais, aos conjuntos musicais informais, aos passeios, ao aprendizado de técnicas novas no esporte, ao artesanato etc.

O animador turístico começa, nesse caso, a se ocupar não com eles, mas com seus filhos. Não se pode esquecer que as mães, na condição de turistas, ainda se afligem com o prolongamento de sua responsabilidade maternal, ou seja, o cuidado com seus filhos. Aliviá-las dessa preocupação, propondo atividades que interessem às crianças e as liberem dessa obrigação, é o primeiro passo do trabalho de animação.

\subsection{Depois}

Poucas equipes de animação turística ocupam-se do depois. E esta é uma falha tanto educativa quanto mercadológica

O retorno à casa após a viagem é marcada pela organização psicológica das experiências, pelo levantamento de novos conhecimentos e amigos etc. Cumpre à animação turística ocupar-se da criação de condições para que tais novas expectativas sejam atendidas. Reuniões posteriores, a pretexto de um contato para reviver os bons momentos da viagem, para troca de fotografias, às vezes podem tornar-se ainda mais gratificantes do que a própria viagem. E nada há de estranho nisso. Afinal, os "filhos do trabalho", como citado na Introdução, são mais preparados para os projetos, para o futuro, do que para o aqui e agora. Num momento de reminiscências, às vêzes, eles têm mais condições de "proustianamente" recuperar o significado de momentos que, na sua vivência, passaram despercebidos.

Essa falha mercadológica deriva do fato de que uma animação no depois pode ser uma forma efetiva de se garantir o retorno, ou melhor, de concretizar as meras intenções que alguns têm de um dia retornar ao mesmo local ou de partir para outras propostas de viagem turística.

\section{O ANIMADOR TURÍSTICO}

Nos últimos tempos, tem-se assistido, de uma maneira notável, a aparição e implantação no turismo, particularmente na hotelaria, de um novo profissional, o animador turístico. Os primeiros animadores eram pessoas que, a princípio, não tinham em absoluto um perfil definido, nem conceitualizado. Simplesmente realizavam alguma atividade, "show"-apresentação, com o objetivo de tornar mais agradável a estada de clientes nos estabelecimentos hoteleiros. Mas, obviamente, eram pessoas atípicas e que não se enquadravam em nenhum organograma hoteleiro. Todavia, pouco a pouco, foi-se reconhecendo sua importância e evidentemente exigindo-se uma profissionalização.

O tempo, como tantas outras coisas, vai perfilando e clareando as funções e as responsabilidades desse profissional. Hoje entende-se que a existência de técnicos-profissionais especializados em animação turística é necessária e fundamental, porque uma tarefa de tal importância não se pode prestar à improvisação.

Dos primeiros entusiastas, aficcionados, recrutados entre os inúmeros guias de agências de viagens que operavam com turistas internacionais $€$ que falavam dois ou três idiomas, que realizavam essa 
função, com muito entusiasmo mas com pouca preparação, passa-se à existência de profissionais qualificados e em número crescente, impulsionados quase sempre por iniciativas privadas, mas com resultados não suficientemente satisfatórios.

A demanda crescente, as dificuldades de preparação e formação e a falta de um marco teórico referencial, dificulta em muito o trabalho das pessoas que começam nessa nova profissão, atrativa e repleta de possibilidades. Por isso, faz-se necessário que, aliado ao aparecimento de iniciativas privadas que tentam dar respostas a essa demanda, também se procurem idéias, soluçōes e cursos, para configurar de uma maneira mais estável esse novo profissional, além de propiciar-lhe formação e treinamento adequados

Para tentar definir e delimitar um pouco o animador turístico, Manuel Garcia Blanco ${ }^{3}$ (diretor de animação, em Madrid), desenvolve uma espécie de "marco funcional" a fim de enquadrá-lo mais facilmente. Para ele, o animador turístico num hotel:

- é catalizador de interesses e motivador da participação de grupo, pois, dada a sua situaçáo dentro do hotel é a pessoa mais idônea para lidar com os interesses dos clientes e tentar oferecer-lhes propostas válidas para satisfaçào dos mesmos;
clina

- negocia e coordena a animaçáo e o entretenimento do turista dentro do hotel, realizando e participando da maioria das atividades de fonna ativa, mas o protagonista deve ser, nonnalmente, o cliente;

- é o ponto de encontro entre a demanda turística e a capacidade de oferta do estabelecimento. Frente à direçào deste, deve ser um "tennômetro" do estado de ânimo do turista; deve considerar a animaçào como um departamento a mais dentro do hotel, absolutamente coordenado com o resto dos departamentos, sobretudo com bares, serviços e recepção. ${ }^{3}$

No momento de selecionar as pessoas adequadas para desenvolver este trabalho, há uma série de fatores que devem ser considerados. Em primeiro lugar, fatores de caráter puramente pragmáticos, como domínio de idiomas, idade entre 20 a 40 anos, nível cultural médio-alto, boa aparência etc. Depois busca-se que o animador seja uma pessoa simpática, de reflexos rápidos, facilidade de diálogo, tolerante, criativo, dinâmico, ativo, organizado e líder, sem presunçōes pretenciosas. Não é, portanto, um "showman", ainda que poderia sê-lo, porque não lhe faltam condiçōes e nem recursos para tanto, sua experiência e seus conhecimentos devem ser postos ao serviço do grande objetivo: que o grupo se sinta bem, cômodo, alegre e satisfeito atendido em suas necessidades.

Entre os itens que definiriam seu perfil pessoal, Blanco destaca: simpatia, amabilidade, tolerância, adaptabilidade a situaçòes diversas, resistência a frustraçòcs, capacidade de diálogo e liderança, profundo conhecimento das técnicas $e$ recursos de animaçáo, atitude permanente de aprendizagem, conhecimento do meio aurssicico e hoteleiro, ativ'o e dinâmico, capacidade de improvisação, entusiasta, criativo, com atitudes pennanentes de obseriaçào, capacidade pedagégica etc. ${ }^{3}$

Evidentemente, resulta tarefa quase impossível encontrar uma pessoa com todas as condiçóes acima propostas, mas sempre deve-se tender à perfeição máxima, procurando ao menos pessoas com a maioria dessas características.

\section{ANIMAÇÃO E ORGANIZAÇÃO HOTELEIRA}

\subsection{O que é e como fazer Animação em Hotéis}

A princípio, partindo-se de que o grau de desenvolvimento social e cultural é função do grau de organização de um país, assim também, tende-se a aceitar que o grau de animação integral de um hotel depende da organização do funcionamento total do mesmo e do grau de coordenação de todas as suas atividades. Assim, a aplicação de um programa integral de animação subordina-se à existência prévia de uma estrutura de direção definida nesse sentido. Em um hotel, a animação afeta e repercute em todos os departamentos, portanto, a direção ou gestão de um estabelecimento ou complexo turístico constitui o seu "motor" de desenvolvimento global. A animação converte-se na principal e mais rentável atividade.

A direção de um hotel com animação turística deverá assumir uma série de responsabilidades que, às vezes, constituem novas funções, tats como:

a) quanto ao pessoal/equipe de animação:

- clareza na definição de suas competências;

- colaboração de outros departamentos do hotel;

- informações sobre possibilidades de progresso na carreira, em termos de promoções e cargos.

(*) Na visāo francesa, o sociólogo Joffre Dumazedier ${ }^{\dagger}$. fixa as características dos anima dores em três itens: competência técnica. grande dinamismo social e inovadores. quer dizer, são "marginais" em relação à norma cultural dominante no seu meio. substumdo-as por normas culturais que julgam superiores do ponto de vista de invenção, da criação e da pesquisa cultural. 
b) quanto a recursos materiais:

- avaliação contínua para o seu ótimo aproveitamento;

- análise de novas possibilidades;

- coordenação da aquisição de equipamento específico para a animação.

c) em geral:

- planejamento e realização de atividades;

- pesquisa sobre o grau de satisfação da clientela;

- conhecimento de mercado do tipo de tecnologia necessária à animação.

O gerente de uma hotel turístico deverá valorizar e viabilizar a criação de condiçōes internas e externas para a animação. Caso não es. teja plenamente convencido dessa necessidade, a animação não exis. tirá ou resultará contraproducente.

A qualidade e o atrativo de animação não justifica o descaso dos demais serviços oferecidos pelo hotel. Realmente é muito difícil "animar" uma clientela que esteja sofrendo deficiência na alimentação, por exemplo.

Nesse sentido, a direção de u m hotel com animação deverá atentar para:

a) o planejamento e a organização de todas as atividades de animação;

b) a duração, a compatibilidade e o equilíbrio entre as diferentes atividades;

c) as pesquisas sobre o grau de aceitação ou não dessas atividades pelos hóspedes;

d) a adequada publicidade e "merchadising";

e) a qualidade e adequação dos materiais, bem como seu controle $\theta$ conservação;

f) a orientação e colaboração direta e recíproca entre a direção e 0 departamento da animação.

\subsection{A Equipe do Setor de Animação}

O setor de animação de um hotel de porte médio (cerca de 200 unidades habitacionais) não pode ser constituído por uma única pes soa, para atender com dedicação, profissionalismo e qualidade a todos os hóspedes. Atualmente a animação de um hotel com capacidade para hospedagem de $5(0)$ pessoas comporta, no mínimo, dois profissio nais. Esse número aumenta proporcionalmente à capacidade do hotel. chegando a quatro ou cinco, em hotéis com cerca de 100() hóspedes. Naturalmente, a equipe de animação está em função do tipo de instalaçōes e facilidades de cada hotel em particular.

Esse número é ainda determinado pelo tipo de atividade desenvolvida e obviamente. das condiçōes de remuneração oferecidas pelo hotel. Normalmente, começa-se contratando somente um animador, para então contratar-se outros profissionais progressivamente, implantando a animação turístico-hoteleira.

Em qualquer caso, a existência da equipe de animação não somente é exigida pelo volume de trabalho, como pela principal característica da mesma, que é a participação. Em termos de desenvolvimento e até de hierarquia, vem marcada pela experiência e aquisição de técnicas e práticas, além de conhecimento de idiomas, dependendo do hotel e seus respectivos hóspedes.

\section{PERSPECTIVAS}

A animação turística está na moda? Ao que tudo indica, não. Enquanto os produtores culturais (e aqui incluem-se também todos os que se ocupam da criação de programas turísticos ou de equipamentos de lazer turístico) estiverem ativos, sempre haverá a necessidade de u ma mediação entre eles e o público.

Essa mediação é educativa. Aceita-se, por ora sem reservas, essa expressão que deve provocar "engulhos" em alguns empresários. Sim, educativa na medida em que amplia horizontes, aumenta o arsenal de formas criativas de uso do tempo livre, prepara os indivíduos para desfrut

decidıdamente, poucos estão realmente preparados.

A formação de recursos humanos surge, no entanto, como o grande obstáculo que se coloca no momento. A recreação continua no plano incômodo de atividade banal, sem exigir um perfil definido do profissional que a execuła, nem técnicas e métodos adequados. As escolas de educação física, de comunicação, de turismo, hotelaria, os grandes celeiros desses profissionais, ainda vêem com indisfarçado preconceito e reserva esse campo de atividades.

\section{REFERÊNCIAS BIBIJOGRÁFICAS}

1. MARCUSE. herhert. Erose elvilização. Rio de Janeiro. Guanahara. 1960 apoio).
ando de la. Que es la animatur? Madrid. SPIC. 1983. p.2 (material de 
3. BLANCO, Manuel Garcia. La figura del animutur turistico. Revista DIRHOS, Madrid, ANDH, no 5. 1984, p. 6-7.

4. DUMAZEDIER. Joffre \& SAMUF:L. Nicole. Sociedade Educativa c poder cultural, França, 1976. 